\section{La violencia contra mujeres en comunidades transnacionales de San Luis Potosí, México: un problema de salud pública}

\author{
Violence against women in transnational communities \\ in San Luis Potosí, Mexico: a public health problem
}

\author{
A violência contra as mulheres nas comunidades \\ transnacionais de San Luis Potosí, México: um \\ problema de saúde pública
}

Yesica Yolanda Rangel Flores 1,2

\begin{abstract}
Resumen
La violencia contra las mujeres es un problema mundial, dado el impacto que tiene en la calidad de vida de quienes la viven, bajo la complicidad de una cultura patriarcal y un Estado que la invisibiliza. Este artículo busca hacer visibles los contextos de violencia en que viven mujeres "parejas de migrantes" en las localidades de origen, problematizando cómo atentan contra su salud física y mental. Se trató de un estudio cualitativo con enfoque en la antropología interpretativa, con 21 mujeres de localidades rurales y urbanas de San Luis Potosí, México; se aplicaron entrevistas desde el marco de historia de la vida cotidiana y análisis de discurso. Los resultados muestran que las mujeres viven mayor violencia cuando sus parejas migran, nuevas formas de violencia se cometen contra ellas, y los ámbitos en que la sufren incluyen el doméstico y el comunitario. La violencia contra las mujeres constituye un problema de salud pública que debe atenderse desde un marco sensible a las dinámicas sociales y culturales que caracterizan los contextos en que se aplican los programas de salud.
\end{abstract}

Violencia Contra la Mujer; Salud de la Mujer; Emigración e Inmigración

\author{
1 Universidad Autónoma de \\ San Luis Potosí, San Luis \\ Potosí, México. \\ 2 El Colegio de San Luis A.C. \\ San Luis Potosí, México.
}




\section{Introducción}

La violencia contra las mujeres ha tenido un proceso de visibilidad institucional largo y complejo, y en el ámbito sanitario esto no ha sido excepción $1,2,3$, aún persisten dificultades para que los actores de salud den cuenta de la responsabilidad que tienen en su prevención y atención, en la notificación de casos y en la salvaguarda de las mujeres que la viven 4,5,6.

En este contexto, hablar de violencia contra las mujeres exige reconocer que existen asimetrías intra-género que potencian la probabilidad de ser agredida, ello resulta de utilidad para elaborar políticas públicas en salud que reconozcan contextos particulares que sirven como caldo de cultivo para cometer violencia contra este grupo poblacional. Ejemplo de lo anterior, lo representa el fenómeno de la migración internacional, situación a la que han sido adjudicadas diversas problemáticas de salud y que han dado pie a estrategias binacionales para contener enfermedades infecciosas emergentes y reemergentes como la malaria, la tuberculosis y la infección por VIH/SIDA para quienes transitan entre los Estados Unidos de América y México 7,8,9,10.

Como parte de estas estrategias, México ha impulsado el Programa de Acción Específico Vete Sano, Regresa Sano, que incorpora una serie de objetivos y estrategias que buscan a través de servicios de promoción, prevención y atención, reducir los impactos que la movilidad migratoria trae consigo no sólo en la salud física, también en la psicológica y social 11.

En este contexto, sin embargo, las problemáticas que enfrentan las mujeres que "esperan" en las localidades de origen el retorno de sus parejas han sido históricamente invisibilizadas por los servicios de salud; situación que puede tener origen en los discursos ambiguos que se erigen sobre las experiencias que vive esta población, y es que mientras algunos autores señalan la migración masculina cómo una oportunidad de "empoderamiento" para las mujeres que habitan las comunidades transnacionales 12,13, otros autores reconocen que dicha movilización reafirma las desigualdades de género y asimetrías de poder en las comunidades de origen 8,9 .

La migración trastoca el ámbito de lo individual, pero también de lo social, de lo cotidiano como de lo político, y es en este complejo entramado, donde lo personal termina siendo público, dentro de contextos en los que las familias y las dinámicas de quien las conforman se reconfiguran para adecuarse a las nuevas realidades de la migración ${ }^{14}$. En el contexto anterior, la migración trae consigo una doble vulnerabilidad para las mujeres que permanecen en las localidades de origen, quienes deben adoptar de manera súbita nuevas representaciones de la familia y asumir nuevos roles sociales.

Una de las estrategias que más se aplica en las comunidades para que la migración funcione, es el hecho de exigir a las mujeres cohabitar en la residencia patrivirilocal, cuidadas por los padres y familias de sus parejas dentro de espacios de los que no son propietarias, y en los que deben aprender a someterse a nuevas formas de poder, algunas veces francamente violentas, otras tantas, enmarcadas en una solidaridad filial que las compromete a ceder en sus tomas de decisiones respecto a la educación de sus hijos, la administración de las remesas o incluso a renunciar al ejercicio de sus derechos humanos 15 .

Diversos acercamientos han evidenciado que los contextos en que estas mujeres esperan el retorno de sus parejas, está saturado de condiciones que atentan contra su salud física, mental y sexual-reproductiva 16,17 . La violencia en los espacios familiares y comunitarios, parece reforzarse cuando los varones no están presentes en las localidades, en contextos que sostenidos por imaginarios patriarcales, legitiman que en la búsqueda incesante por controlar a las mujeres y sus cuerpos, se niegue a las mismas el acceso a participar del empleo remunerado, participar de redes sociales, y acercarse a los servicios de salud 18,19 .

En el contexto antes señalado, resulta relevante conocer ¿cuál es la situación de violencia que viven las mujeres de comunidades transnacionales?; ¿cómo se modifican (si es que lo hacen) las dinámicas de violencia que estas mujeres viven, en la ausencia de sus parejas? y icuáles son los tipos de violencia que más experimentan? Responder estas preguntas resultara relevante en dos sentidos, primero desde el punto macro social, en el compromiso de dar respuesta a tratados y convenciones internacionales que han sido firmados por México para garantizar el acceso de las mujeres a una vida libre de violencia; y segundo, pero no menos relevante, porque el papel de los servicios de salud en la atención integral al problema de la violencia familiar, según los servicios de salud en México debe ejecutarse en cuatro vertientes: prevención, detección, atención y salvaguarda; intervenciones que requieren un conocimiento profundo sobre las dinámicas sociales y culturales en que se gesta la violencia.

Con base en lo anterior, el objetivo de este estudio fue documentar las experiencias de violencia que viven mujeres de comunidades transnacionales, así como evidenciar de qué forma se reconfiguran estas dinámicas en la ausencia de sus parejas. 


\section{Metodología}

Se realizó un estudio cualitativo, con fundamento en la antropología interpretativa de Clifford Geertz, cuyo principal postulado gira en torno a cómo las construcciones culturales diferentes de la realidad afectan la acción social. Un marco teórico que conduce a la reflexión en torno a la extrema complejidad en que se desarrolla la agenda de los actores, a partir las estructuras macro sociales de los contextos particulares 20,21,22.

El trabajo de campo se realizó de noviembre de 2011 a noviembre de 2013 en dos comunidades de San Luis Potosí, México, una rural perteneciente a la región media y una urbana en la región centro. Las localidades fueron seleccionadas por representar dos regiones distintas del estado y caracterizarse por alta participación migratoria, según recientes estadísticas del Instituto Nacional de Estadística, Geografía e Informática 23.

El trabajo de campo se inició mediante entrevistas en grupos focales con mujeres "parejas de migrantes" de ambas localidades y, dado que esta fue una estrategia aplicada con el único fin de identificar a las informantes, en el presente artículo no se presentan resultados de las entrevistas grupales. El uso de grupos focales como estrategia para seleccionar posibles informantes ha sido documentado como válido por diversos autores $24,25,26$.

Durante la fase de trabajo en grupos focales se realizaron cuatro entrevistas, dos en cada una de las localidades, el número de participantes en cada uno de los grupos osciló entre siete y diez, incluyendo mujeres que fuesen parejas de migrantes activos o varones que hubiesen migrado en alguna etapa de su vida con patrón de migración circular, y que ellas no hubiesen participado de la migración conjunta con sus parejas.

Durante los grupos focales se aplicó una guía de entrevista semiestructurada que exploró cuatro dimensiones: (1) La migración en la localidad, (2) Los riesgos de la migración, (3) Ser mujer pareja de migrante, y (4) Cambios en la cotidianeidad, nuevos roles y sentimiento hacia ellos. No se abordó de manera directa el tema de la violencia, en función del reconocimiento de que en el contexto mexicano prevalece el estigma contra las mujeres que la padecen, y ello podía condicionar que las mujeres se sintieran intimidadas para compartir sus experiencias. Esta estrategia también responde al hecho de que algunos tipos de violencia (psicológica, patrimonial, sexual) suelen ser invisibles a los propios ojos de las mujeres, en medida que se legitima en términos de usos y costumbres de los diferentes contextos, por esta razón es que se consideró más relevante que las mujeres hablasen en general de sus vidas cotidia- nas, mientras la investigadora iba rastreando la práctica de los diferentes tipos de violencia que padecían, incluyendo la simbólica.

Mediante las entrevistas grupales fue posible identificar a las mujeres que participarían en el estudio, invitando a participar como informantes a quienes cohabitaran con las familias de sus parejas o consanguíneas, "encargadas" como era mencionado por muchas de ellas. También fue una característica para su inclusión, el hecho de que narraran experiencias de violencia por parte de su pareja o la familia con quien cohabitaba.

Para las entrevistas individuales se recurrió a la realización de entrevistas en profundidad, desde la metodología de "historias de la vida cotidiana”, ambas técnicas posibilitan explorar las cotidianeidades para el reconocimiento de prácticas que en el marco de los imaginarios locales y en su carácter de rutinarias y secuenciales, las mujeres llegan a "normalizar" y no identifican como violentas $27,28,29$.

En las entrevistas en profundidad se exploraron cuatro dimensiones particulares: (1) Ser mujer en una localidad de tradición migratoria, (2) Ser mujer pareja de migrante, (3) Expectativas, miedos e incertidumbres cuando la pareja migra, y (4) Exponerse sin migrar, la configuración de nuevos riesgos (la violencia como riesgo de la migración).

Mediante la aplicación del criterio de saturación teórica, tuvo a bien implementarse un total de 21 historias de vida, con la mayoría de las mujeres se realizaron dos entrevistas, sin embargo, hubo casos en los que se entrevistó hasta en cuatro ocasiones, la duración promedio de las entrevistas fue de 110 minutos, todas fueron grabadas y transcritas personalmente. La saturación teórica hace referencia a la pertinencia de continuar profundizando sobre algún tema en particular en medida que aparecen nuevos datos, así como interrumpir la recolección de información una vez que no aparecen datos novedosos durante las entrevistas 30 .

La información recabada fue analizada a través de análisis del discurso, para el que se recurrió al método de Klechterman, marco útil para realizar el análisis y la contrastación teórica. La codificación desde este marco se realizó en dos vertientes, una primera de carácter individual y vertical, en la que se recuperó la singularidad y riqueza de cada relato con la finalidad de conocer a profundidad los relatos individuales e identificar tanto las categorías de análisis como los patrones intra-caso; la segunda vertiente, fue de naturaleza colectiva u horizontal, con el fin de hacer una lectura transversal y comparativa entre los relatos de las mujeres, con el fin de encontrar patrones concurrentes, coincidencias y divergen- 
cias que permitiesen identificar ejes temáticos analíticos inter-caso, que se erigirían como los datos a trabajar en la búsqueda de significados en los relatos 31 .

En este estudio se cumplieron los principios éticos contenidos en la Declaración de Helsinki y la Ley General de Salud en México. Se trató de un estudio de riesgo mínimo en función de que se exploraba y profundizaba sobre experiencias posiblemente dolorosas, razón por la que planteó la posibilidad y el compromiso ético de suspender las entrevistas cuando la estabilidad emocional se valorara en riesgo o las mujeres manifestaran el deseo de suspender su participación. Anticipando la existencia de respuestas emocionales adversas, en todo momento se mantuvo vinculación con personal de psicología de los servicios de salud del estado, y la investigadora se capacitó en el manejo de contención emocional básica. Se solicitó por escrito el consentimiento informado y se garantizó en todo momento la confidencialidad sobre la identidad de los informantes.

El proyecto fue evaluado, aprobado y supervisado en su operación por el Comité de Ética e Investigación de la Secretaría de Salud del Estado de San Luis Potosí, en el que se registró el proyecto en octubre de 2011, registrándose en el expediente número 008603.

\section{Resultados}

\section{Sobre el escenario y las informantes}

San Luis Potosí figura entre las diez entidades con mayor participación migratoria hacia los EE.UU., con un índice migratorio clasificado como "alto" $(0,73)$ que lo posiciona en el sexto lugar en la participación migratoria nacional y la captación de remesas familiares $(6,58 \%){ }^{32}$. La relación que San Luis Potosí mantiene con los EE.UU. posee tanto una tradición histórica como emergente, con algunas diferencias en las dinámicas migratorias de las cuatro regiones del estado, y es en este sentido es que resultó pertinente elegir dos localidades que perteneciesen a regiones distintas de San Luis Potosí: Rancho Nuevo, que se ubica en Soledad de Graciano Sánchez, municipio de la región centro, donde se observa una participación migratoria baja y relativamente reciente; y La Veinte, que se ubica en Ciudad Fernández, dentro de la región media, caracterizada por haber hecho de la migración una de sus principales fuentes de ingreso y donde en algunos de sus municipios las remesas llegan a ser superiores al $30 \% 33$.

En lo que se refiere a las dinámicas en que se practica la migración, se encontró que si bien en ambas localidades se presentan casos de mi- gración clandestina, los varones de La Veinte parecen menos interesados en participar de esta modalidad, principalmente, debido a la experiencia que tienen movilizándose por convenios laborales a través de la Secretaría de Relaciones Exteriores. La dinámica en que se da la migración incide de manera relevante en las experiencias que enfrentan las mujeres en sus vidas cotidianas y los impactos que trae la migración de sus parejas en sus realidades. Por lo anterior es que resulta necesario conocer las características de vida conyugal y dinámica migratoria (Tabla 1), así como las características sociodemográficas de las informantes (Tabla 2).

\section{Sobre las experiencias de violencia}

En las narrativas que las mujeres compartieron se identificó que una gran parte de ellas "viven la espera" cual Penélopes, atendiendo los criterios que los varones y las familias con quienes se "dejan encargadas" establecen para esperar el retorno de sus parejas. En estos contextos, son diversos los tipos y modalidades de violencia que se recrudecen en sus vidas cotidianas y en donde se incluyen desde la simbólica hasta la física, pasando por la económica y psicológica.

\section{- Violencia simbólica: "la justificada"}

Bourdieu describió la violencia simbólica como una estrategia sutil que victimiza, sin percatarse agresiva, y que incluso llegar a legitimarse "válida" por quienes la padecen 34 . En este sentido, se encontró mujeres que encuentran pertinente el ser "cuidadas" y "vigiladas" en su comportamiento moral, aunque en este "cuidado" se implique la violación más hartera a sus derechos humanos, sexuales y reproductivos. Padres, madres, suegras y suegros son responsables de vigilar el comportamiento moral de estas mujeres, en un periodo en el que la sexualidad de estas, emerge cómo una variable que es preciso vigilar, contener y salvaguardar.

Las propias madres de las mujeres, sus referentes de género más inmediatos, legitiman la necesidad de regular sus comportamientos acordes a una mirada social que se endurece en la ausencia del varón.

“Ellas que aún tienen edad [para ser sexualmente activas, según el imaginario de que la sexualidad tiene un vínculo ineludible con la reproducción] tienen que portarse a raya, nada de andar en la calle dando lugar a comentarios, porque por lo mismo que les ven jóvenes y solas, $y$ no falta él que espera que le den entrada, ahora sí que mientras están solas aquí ni amigos ni nada... andarse derechitas" (P10, La Veinte). 
Tabla 1

Caracterización de la conyugalidad y movilidad migratoria.

\begin{tabular}{|c|c|c|c|}
\hline Informante & Tipo de unión & Vida en pareja (años) & Ciclos de movilidad migratoria \\
\hline \multicolumn{4}{|c|}{ Mujeres de la localidad La Veinte } \\
\hline 1 & Unión libre & 36 & 8 meses en EE.UU. y 4 meses en México, durante 16 años \\
\hline 2 & Casada & 25 & $\begin{array}{l}\text { Hace } 10 \text { años regresó por } 4 \text { años, y permaneció } 3 \text { años, hace año y } \\
\text { medio que se fue a EE.UU. }\end{array}$ \\
\hline 3 & Casada & 11 & $\begin{array}{l}8 \text { meses EE.UU. y } 4 \text { meses en México durante } 10 \text { años, tiempo de } \\
\text { ausencia máxima de } 3 \text { años }\end{array}$ \\
\hline 4 & Casada & 21 & 8 meses EE.UU. y 4 meses en México durante 19 años \\
\hline 5 & Casada & 3 & Se fue hace dos años y no ha retornado de los EE.UU. \\
\hline 6 & Casada & 17 & 8 meses EE.UU. y 4 meses en México durante 10 años \\
\hline 7 & Casada & 25 & $\begin{array}{l}\text { Inició la migración antes del matrimonio con ciclos de } 8 \text { meses en } \\
\text { EE.UU. y } 4 \text { meses en México durante } 25 \text { años }\end{array}$ \\
\hline 8 & Casada & 7 & Hace un año migró a EE.UU. y no ha retornado \\
\hline 9 & Casada & 35 & $\begin{array}{l}8 \text { meses en EE.UU. y } 4 \text { meses en México durante } 30 \text { años, desde hace } \\
\qquad 5 \text { años no retorna }\end{array}$ \\
\hline 10 & Casada & 7 & $\begin{array}{l}\text { Migró hace } 4 \text { años, regresó } 9 \text { meses y volvió a migrar, hace dos años } \\
\text { que no retorna de los EE.UU. }\end{array}$ \\
\hline 11 & Casada & 30 & $\begin{array}{c}\text { Hace } 13 \text { años migró por } 3 \text { años, hace } 5 \text { por } 2 \text { años, ahora } \\
\text { está en México }\end{array}$ \\
\hline \multicolumn{4}{|c|}{ Mujeres de la comunidad Rancho Nuevo } \\
\hline 1 & Casada & 29 & $\begin{array}{l}\text { Hace } 12 \text { años se fue por tres años y regresó, ahora hace dos años que } \\
\text { no retorna desde EE.UU. }\end{array}$ \\
\hline 2 & Casada & 21 & Hace 10 años migró por 4 años, ahora está en México \\
\hline 3 & Casada & 18 & $\begin{array}{c}\text { Desde hace } 12 \text { años se fue por } 2 \text { años, regresó dos meses y retornó a } \\
\text { EE.UU. por } 2 \text { años más, ahí permanece }\end{array}$ \\
\hline 4 & Casada & 13 & Hace 10 años se fue por 3 años, ahora está en México \\
\hline 5 & Casada & 27 & $\begin{array}{l}\text { Hace } 16 \text { años se fue por dos años, regresó, y se volvió a ir por tres } \\
\text { años, ahora lleva } 8 \text { meses en EE.UU. }\end{array}$ \\
\hline 6 & Unión libre & 13 & $\begin{array}{l}\text { A lo largo de } 12 \text { años ha migrado } 6 \text { ocasiones con el periodo más } \\
\text { largo de ausencia de } 4 \text { años, ahora está en EE.UU. }\end{array}$ \\
\hline 7 & Unión libre & 14 & Hace 8 años por 4 años, ahora está en México \\
\hline 8 & Unión libre & 8 & $\begin{array}{c}\text { Hace } 7 \text { años migró por } 2 \text { años a EE.UU., regresó y se volvió a ir otros } 2 \\
\text { años y medio, donde permanece }\end{array}$ \\
\hline 9 & Casada & 19 & $\begin{array}{c}\text { Hace } 18 \text { años migró por } 4 \text { años, regresó, y retornó a EE.UU. por } 7 \\
\text { años, ahora está allá }\end{array}$ \\
\hline 10 & Casada & 12 & Hace 4 años se fue 2 años, volvió a intentarlo sin éxito \\
\hline
\end{tabular}

La vigilancia de las familias se justifica necesaria, para controlar una sexualidad que no se reconoce personal, sino un espacio donde tiene injerencia lo público; una sexualidad que se vive cómo un bien simbólico que atañe a sus parejas, hijos y familias, sabiéndose insertas en contextos en los que su comportamiento sexual influencia no únicamente sobre su reputación personal sino incluso la familiar y social. En dicho marco, las mujeres son habilitadas para compartir socialmente sus derechos sexuales y reproductivos, cuestión que entorpece e incluso obstaculiza, la negociación de los asuntos relativos a su salud sexual y reproductiva.

Conforme las narrativas profundizan, nuevos hallazgos ponen en jaque la idea de que la vigilancia responda exclusivamente a un interés de las suegras, algunas mujeres narran cómo en la ausencia de la suegra por muerte o alejamiento, se recurre a nuevas estrategias para mantener vigilados sus comportamientos, recurriendo a los hijos como aliados. 
Tabla 2

Características sociodemográficas de las participantes.

\begin{tabular}{|c|c|c|c|c|c|c|c|}
\hline \multirow[b]{2}{*}{ Informante } & \multicolumn{2}{|c|}{ Mujeres de La Veinte } & \multirow[b]{2}{*}{ Ocupación } & \multicolumn{4}{|c|}{ Mujeres de Rancho Nuevo } \\
\hline & Edad (años) & Escolaridad & & Informante & Edad (años) & Escolaridad & Ocupación \\
\hline P1 & 22 & $\begin{array}{l}\text { Secundaria } \\
\text { incompleta }\end{array}$ & Ama de casa & P1 & 51 & $\begin{array}{c}\text { Primaria } \\
\text { incompleta }\end{array}$ & Venta de alimentos \\
\hline $\mathrm{P} 2$ & 51 & $\begin{array}{c}\text { Primaria } \\
\text { incompleta }\end{array}$ & Afanadora & P2 & 38 & $\begin{array}{c}\text { Primaria } \\
\text { incompleta }\end{array}$ & Ama de casa \\
\hline P3 & 41 & $\begin{array}{c}\text { Primaria } \\
\text { incompleta }\end{array}$ & Auxiliar en la iglesia & P3 & 37 & $\begin{array}{c}\text { Primaria } \\
\text { incompleta }\end{array}$ & Empleada \\
\hline P4 & 31 & $\begin{array}{l}\text { Primaria } \\
\text { completa }\end{array}$ & Ama de casa & P4 & 31 & $\begin{array}{c}\text { Secundaria } \\
\text { completa }\end{array}$ & Ama de casa \\
\hline P5 & 41 & $\begin{array}{l}\text { Primaria } \\
\text { completa }\end{array}$ & Venta de alimentos & P5 & 44 & $\begin{array}{l}\text { Primaria } \\
\text { completa }\end{array}$ & Ama de casa \\
\hline P6 & 20 & $\begin{array}{l}\text { Secundaria } \\
\text { incompleta }\end{array}$ & Ama de casa & P6 & 28 & $\begin{array}{l}\text { Secundaria } \\
\text { incompleta }\end{array}$ & $\begin{array}{c}\text { Negocio de } \\
\text { papelería }\end{array}$ \\
\hline P7 & 37 & $\begin{array}{c}\text { Secundaria } \\
\text { completa }\end{array}$ & Ama de casa & P7 & 28 & $\begin{array}{l}\text { Secundaria } \\
\text { incompleta }\end{array}$ & Pepenadora \\
\hline P8 & 45 & $\begin{array}{c}\text { Primaria } \\
\text { incompleta }\end{array}$ & Venta de alimentos & P8 & 23 & $\begin{array}{c}\text { Secundaria } \\
\text { completa }\end{array}$ & $\begin{array}{l}\text { Trabajadora } \\
\text { doméstica }\end{array}$ \\
\hline P9 & 22 & $\begin{array}{l}\text { Primaria } \\
\text { completa }\end{array}$ & Ama de casa & P9 & 36 & $\begin{array}{c}\text { Secundaria } \\
\text { completa }\end{array}$ & Ama de casa \\
\hline P10 & 51 & $\begin{array}{l}\text { Primaria } \\
\text { completa }\end{array}$ & Ama de casa & P10 & 28 & $\begin{array}{l}\text { Secundaria } \\
\text { incompleta }\end{array}$ & Ama de casa \\
\hline P11 & 45 & $\begin{array}{l}\text { Primaria } \\
\text { completa }\end{array}$ & Ama de casa & & & & \\
\hline
\end{tabular}

"Me casé con un hombre que no me deja salir mucho, ahorita que no está me cuida con los niños, en veces me voy pa Rioverde y me marca al celular y me dice - ¿¿onde tas mija?'- le digo 'acá en Rioverde' -y me dice '¿con quién andas?'- le digo 'con el niño' - y me dice 'a ver pásamelo' y tengo que pasarle el niño... nunca ando sola, si no hay niños como en la mañana que se van a la escuela, no salgo, me voy hasta en la tarde con ellos y es que solo así él está a gusto que yo ande todo el tiempo con los niños" (P4, La Veinte).

Las mujeres narran la utilización de sus propios hijos como forma de control moral, niños que sin alcanzar la mayoría de edad deben asumirse guardias morales de sus madres, coartando su libertad y recordándoles de manera constante, que con independencia de su etapa de vida y madurez, resulta pertinente y necesario vigilar su valor simbólico más importante, su sexualidad.

\section{- Violencia psicológica: "aislamiento impuesto"}

La violencia psicológica también protagoniza gran parte de las historias de estas mujeres, una de las modalidades más narradas es la restricción que la comunidad y familia hace respecto a su libertad para acceder y frecuentar sus redes de apoyo social. Respecto a este punto aparece el rumor como una de las estrategias más usadas por las suegras, un rumor que focalizado sobre su comportamiento moral, emerge cómo una estrategia poderosa para regular su comportamiento, principalmente, porque saca ventaja de la complejidad que implica la comunicación para las parejas en los contextos de la migración.

Las mujeres temen a los rumores que en torno a su comportamiento puedan construirse, en función del poder que el mismo ha mostrado en casos de abandono.

"Mi suegra decía que yo andaba con otro hombre, que no atendía bien a las niñas, hasta la fecha dice que ella misma me encontró en la cama con el otro y eso se lo dijo a él [esposo], pero no es cierto [rompe en llanto]... él le creyó a ella, cuando regresó me dijo que ya no se iba a juntar conmigo porque mucha gente le había dicho que yo andaba así... su mamá ya no quería que volviera conmigo" (P6, Rancho Nuevo).

En los casos de otras mujeres se recurren a estrategias aún más violentas para ejercer el control, son retiradas de sus ciudades de origen en la 
búsqueda por despojarlas de sus redes sociales y familiares.

"Cuando le dije que ya no quería estar con su mamá, me dijo que entonces con la mía tampoco...nomás un día me habló y me dijo que había comprado un 'pie de casa' pero en San Luis Potosí y no en Matamoros, que me la compraba porque allá nunca iba a poder comprar nada y que si quería me viniera para acá... Cuando llegué aquí no había luz ni agua, era puro monte y así me quedé aquí sola con las niñas" (P9, Rancho Nuevo).

Sin embargo, no todas las mujeres toleran las vicisitudes que trae consigo el ser "encargadas", algunas desarrollan fortaleza para dejar de cohabitar en la residencia patrivirilocal, accediendo con ello a una vida menos estricta y más personal. En la mayoría de los casos, la determinación por dejar la casa de los suegros, deriva de conflictos de pareja provocados por juicios y apreciaciones que suegros hacen sobre el comportamiento moral de estas mujeres. Historias dramáticas que incluyen formas de violencia que llegan a afectar las relaciones de pareja, la autoestima de las mujeres e incluso ponen en riesgo su vida.

"Creo que me celaba más mi suegro que mi esposo, una vez que fuimos a la fiesta del pueblo y un muchacho me dio el paso, yo le agradecí y entonces el viejito andaba 'tomao' [alcoholizado] y que me grita 'jija de tu repinche madre así te quería encontrar desgraciada, puta, infeliz' yo no hallé en ese momento que contestar porque yo me tullí [paralizó], llegando a la casa me dio hasta que me sangró, ya estaba bien viejito, pero pegaba todavía bien fuerte" (P11, La Veinte).

\section{- Violencia económica: "hacer buen uso de un dinero ajeno"}

Las mujeres refieren que las remesas se constituyen en una herramienta que sus familias consanguíneas o de sus parejas, usan para violentarlas; en este sentido, es común que los varones envíen las remesas a sus madres, quienes son responsables de vigilar su administración, una decisión que no hace más que reiterar en lo social, la imagen de esposas incapaces de tomar decisiones acertadas sobre la cuestión económica, en tanto reafirman la relación de poder que se juega entre suegra-nuera.

"El niño una vez se me moría y éste [esposo] no me mandaba porque andaba de borracho [alcoholizado], entonces fui con ella [la suegra] y le dije que si me podía conseguir dinero y me dijo 'no, yo no te consigo ningún pinchi dinero'... después me enteré que él me había mandado 50 dólares, pero como se los mandaba a ella pa que me los diera, ella no me los entregaba para hacerme renegar [sic]" (P4, La Veinte).
Damos cuenta que las remesas en sí mismas no potencian la autonomía de estas mujeres, algunas veces recrudecen su condición de inequidad y desigualdad, quien recibe las remesas y las administra tiene poder sobre la satisfacción de las necesidades básicas y en él caso de esta mujer incluso sobre la vida.

Son escasas las mujeres que se asumen partícipes en la administración de las remesas y si bien en dicho sentido evidencian una percepción de mayor estima y logro, resulta obligado reconocer que esta "administración" ocurre en un marco en el que no les compete tomar decisiones respecto a las inversiones, sino únicamente ejecutar las indicaciones que sus parejas giran al respecto.

Algunas de las mujeres en la búsqueda de enfrentar su vulnerabilidad económica buscan insertarse en actividades económicas formales o informales, sin embargo, participar de actividades remuneradas no depende exclusivamente de su decisión, sino de las opiniones o determinaciones que sus parejas hagan al respecto, los que en su mayoría les niegan este derecho argumentando que dicha incursión traerá consigo menor atención en los hijos, postergación de las tareas domésticas o incluso la posibilidad de conocer otros hombres.

Pese a estas condiciones, es necesario reconocer el caso de mujeres rurales que han logrado incursionar en la esfera productiva, tras haber convencido a sus parejas de la posibilidad de acceder a ingresos económicos sin "desatender" el cuidado del hogar y de los hijos. Por otro lado, emerge una nueva categoría, la responsabilidad de la mujer rural en el trabajo agrícola y ganadero, tarea que debe atender en función de la migración de la pareja. En este contexto, ya no sólo se les niega la posibilidad de incursionar en empleos remunerados por el riesgo de desatender el cuidado de los hijos y el hogar, se implica también la posibilidad de que por ello deje de ocuparse de la siembra, cosecha y crianza del ganado; actividades que les implican una inversión de tiempo y energía, aun cuando no les implica un reconocimiento social.

\section{Discusión}

Geertz en una de sus obras más relevantes "la ideología como sistema cultural” señala la importancia de dimensionar la magnitud simbólica de la cultura en el actuar social de los sujetos 20,21,22, en este sentido, es imposible impactar en el problema de la violencia contra las mujeres, sin problematizar que no se trata de una práctica individual entre agresores y víctimas, sino 
un problema que se sustenta y reproduce en una ideología patriarcal que naturaliza las desigualdades de poder entre hombres y mujeres, y que legitima el ejercicio de actos violentos contra las segundas $35,36,37$.

Las narrativas que las mujeres compartieron, evidencian que el ejercicio de la violencia contra este grupo específico no se limita a la pareja, incluye a las familias de sus parejas, sus familias consanguíneas y la comunidad en general; lo que coincide con los hallazgos que otras investigadoras han encontrado en comunidades transnacionales 12,38,39,40.

El rumor es una forma de violencia simbólica que se impone sobre la reputación moral de quienes esperan el retorno de sus parejas, no se juzga a quien desacredita a otra persona, ignorante de la verdad, sino a las mujeres que participan de situaciones en la que su moral puede ser cuestionada. En este tenor, la ausencia del varón potencia la vulnerabilidad social y moral de las mujeres 41,42 .

Bourdieu señaló que en el intento por perpetuar la dominación masculina 36 , el hombre invierte gran cantidad de tiempo y energía en acciones que reivindican su virilidad, ello se evidencia en la dinámica social de ambas localidades, donde los varones en la búsqueda por controlar el comportamiento moral y sexual de "sus" mujeres, encomiendan del cuidado de las mismas a padres y suegros 43 . La vigilancia de las familias consanguíneas o de los varones se justifica necesaria para controlar una sexualidad que no se reconoce personal, sino un espacio donde tiene injerencia lo público, una sexualidad que se vive cómo un bien simbólico que atañe a sus parejas, hijos y familias, sabiéndose insertas en contextos en los que su comportamiento sexual influencia no únicamente sobre su reputación personal, sino incluso la familiar y social 43,44,45

Las mujeres son limitadas no sólo en el capital económico y cultural, sino incluso en relación al capital social, la negación que hacen sus parejas o las familias de sus esposos/concubinos por acceder a redes sociales y de apoyo, potencia su vulnerabilidad frente a problemáticas que van desde la violencia de género, hasta problemas de salud física y mental 12,42.

Las remesas representan más que un valor monetario, un símbolo a partir del que comienzan a entretejerse nuevas relaciones de poder al interior de las familias, la toma de decisiones continúa desarrollándose de manera androcéntrica, reafirmando la vulnerabilidad económica que caracteriza a estas mujeres 39,40 .

El ingreso a la esfera productiva se da condicionada a no renunciar a la responsabilidad socialmente asignada de la economía del cuida- do, punto que las mujeres no cuestionan, quizá porque para dicha función han sido habilitadas desde etapas tempranas de vida y, en función de ello, contemplan naturalizada al género. Las mujeres han tenido que involucrarse en actividades económicas sin relegar las funciones domésticas, aprendiendo a vivir en un marco de desventaja social, en el que deben resignarse a una carga excesiva de funciones $46,47,48$.

\section{Conclusiones}

La intención de este trabajo fue hacer evidente las condiciones de violencia que viven las mujeres parejas de migrantes en sus cotidianeidades, con la intención de aportar precedente para la planeación e implementación de políticas públicas que consideren y atiendan las condiciones de vulnerabilidad que viven quienes, aún sin participar de manera activa en la movilización migratoria, enfrentan relacionado con ella nuevos riesgos para su salud física, mental, sexual y reproductiva.

Los programas de salud y las estrategias que los profesionales de este ámbito realizan con la población no pueden continuar limitados a una perspectiva biomédica, que circunde su actuar en la profundidad o severidad de las lesiones físicas o emocionales que presentan las mujeres que, por suerte o destino, alcancen a llegar hasta los servicios de salud. El personal de salud debe problematizar las aristas sociales y culturales que prevalecen en los contextos, y anticiparse mediante la prevención primaria y secundaria a contener situaciones que merman en la calidad de vida de más del $50 \%$ de la población actual en México y en el mundo (las mujeres).

Los hallazgos obtenidos permiten dilucidar los ambientes saturados de violencias, igual que permiten dar cuenta de cómo las condiciones de violencia estructural en que estas mujeres han crecido obstaculiza el reconocerse violentadas e implementar estrategias para confrontar dichas violencias. Los servicios de salud representan en una gran variedad de casos, la única institución a la que se les permite acercarse a las mujeres que viven violencia, por ello es que el personal de salud debe desarrollar conciencia sobre las oportunidades perdidas que está teniendo en materia de prevención e identificación de casos.

Una limitación del presente estudio es la ausencia de voz de los profesionales del ámbito sanitario, dado que resulta relevante conocer la experiencia que los servicios de salud tienen en la identificación y manejo de los casos de violencia, así como de las estrategias específicas que llevan a cabo con esta población particular en 
materia de atención de la violencia, y de la prevención y la detección oportuna de VIH. Otra de las limitaciones es el uso de grupos focales, como estrategia para la selección de los participantes, toda vez que narrar las experiencias de violencia se constituye en un reto cultural, particularmen-

\section{Agradecimientos}

Gracias a las mujeres que con su tiempo y confianza contribuyen a comprender los procesos sociales que inciden en su salud, y con ello a planear políticas públicas más pertinentes a sus realidades. Beca de El Colegio de San Luis para estudios doctorales/Beca CONACYT para estudios doctorales.

\section{Referencias}

1. Ochoa AM, Calonge RF. La violencia contra las mujeres en la región occidente, México: entre la inoperancia institucional y el conservadurismo social. Acta Sociológica 2014; (65):121-50.

2. Bejarano CM, Arellano GM. Violencia institucional contra las mujeres en el Noroeste de México. Acta Sociológica 2014; (65):97-120.

3. Arteaga BN, Valdés FJ. Contextos socioculturales de los feminicidios en el Estado de México: nuevas subjetividades femeninas. Revista Mexicana de Sociología 2010; 72:5-35.

4. Valdivia IR, Lombana RJ, Lazcano PE, Rojas MR. Monitoreo de la atención a las mujeres en servicios del sector salud 2012. México DF: Instituto Nacional de Salud Pública; 2013.

5. Secretaría de Salud. Norma Oficial Mexicana 046SSA2-2005: violencia familiar, sexual y contra las mujeres. Criterios para la prevención y atención. http://www.inm.gob.mx/static/Autorizacion_Pro tocolos/SSA/Violencia_familiar_sexual_y_con tra_las_mujeres_criterios_par.pdf (accedido el 10/ Nov/2014).

6. Centro Nacional de Equidad de Género y Salud Reproductiva, Secretaría de Salud. Modelo integrado para la prevención y atención de la violencia familiar y sexual (manual operativo). México DF: Secretaría de Salud; 2009. te, cuando las informantes conviven de manera cotidiana en los mismos espacios comunitarios y, en consecuencia, se asumen vulnerables socialmente hablando, al exponer su experiencia en este tipo de prácticas frente a su grupo social inmediato.
7. Leyva FR, Aracena GB, Servan MA. Movilidad poblacional y VIH/sida en Centroamérica y México. Rev Panam Salud Pública 2014; 36:143-9.

8. Juárez-Ramírez C, Márquez-Serrano M, Salgado de Snyder N, Pelcastre-Villafuerte B, Ruelas-González M, Reyes-Morales H. La desigualdad en salud de grupos vulnerables de México: adultos mayores, indígenas y migrantes. Rev Panam Salud Pública 2014; 35:284-90.

9. Leyva R. Movilidad poblacional y VIH. Salud Pública Méx 2013; 55:1-3.

10. MacPherson DW, Gushulak BD, Macdonald L. Health and foreign policy: influences of migration and population mobility. Bull World Health Organ 2007; 85:200-6.

11. Secretaría de Salud. Programa de acción específico: vete sano, regresa sano 2007-2012. http://www. promocion.salud.gob.mx/dgps/descargas 1/pro gramas/vete_sano_regresa_sano.pdf (accedido el 10/Sep/2015).

12. Klein A, Vázquez FE. Los roles de género de algunas mujeres indígenas mexicanas desde los procesos migratorios y generacionales. Journal of Behavior, Health \& Social Issues 2013; 5:25-39.

13. Herrera G. Género y migración internacional en la experiencia latinoamericana: de la visibilización del campo a una presencia selectiva. Política y Sociedad 2012; 49:35-46. 
14. Coubés ML, D’Aubeterre Buznego ME. Los vínculos familiares fuera de la corresidencia: geografía de residencia, intensidad de los contactos y lazos afectivos en la parentela. In: Rabell Romero C, coordinadora. Tramas familiares en el México contemporáneo. Una perspectiva sociodemográfica. México DF: Instituto de Investigaciones Sociales, Universidad Nacional Autónoma de México/El Colegio de México; 2009. p. 97-139.

15. Ariza M, Portes A. La migración internacional de los mexicanos: escenarios y desafíos de cara al nuevo siglo. In: Ariza M, Portes A, coordinadores. El país trasnacional: migración internacional y cambio social a través de la frontera. México DF: Instituto de Investigaciones Sociales, Universidad Nacional Autónoma de México; 2007. p. 11-54.

16. Arias P. Migración internacional y cambios familiares en las comunidades de origen: transformaciones y resistencias. Annu Rev Sociol 2013; 39: 1-23.

17. Caballero M, Leyva R, Ochoa S, Zarco A, Guerrero C. Las mujeres que se quedan: migración e implicación en los procesos de búsqueda de atención de servicios de salud. Salud Pública Méx 2008; 5:241-50.

18. Vizcarra I. A manera de introducción: hacia la formulación de una economía política feminista. In: Vizcarra I, coordinador. Género y poder: diferentes experiencias, mismas preocupaciones. México DF: Programa Universitario de Estudios de Género, Universidad Autónoma del Estado de México; 2005. p. 7-28.

19. Rangel FY. Prácticas de autocuidado sexual y reproductivo en mujeres "parejas de" migrantes internacionales de San Luis Potosí, México. Cult Cuid 2014: 18:82-92.

20. Geertz C. Géneros confusos. La refiguración del pensamiento social. In: Reynoso C, compilador. El surgimiento de la antropología posmoderna. Barcelona: Gedisa; 2003. p. 63-77.

21. Geertz C. La interpretación de las culturas. Barcelona: Gedisa; 2000.

22. Micheelsen A. "I don't do systems": an interview with Clifford Geertz. Method \& Theory in the Study of Religion 2002; 14:2-20.

23. Instituto Nacional de Estadística, Geografía e Informática. Migración internacional de México al cuarto trimestre de 2012. Boletín de Prensa 2013; 111/13, 2 abr.

24. Toro JI, Parra RR. Método y conocimiento: metodología de la investigación. Medellín: Universidad EAFIT; 2006.

25. Liamputtong P. Focus group methodology: principles and practice. London: SAGE; 2011.

26. Hennink M. Focus group discussions: understanding qualitative research. New York: Oxford University Press; 2014.

27. Reynaga S. Perspectivas cualitativas de investigación en el ámbito educativo. La etnografía y la historia de vida. In: Mejía R, Sandoval S, coordinadores. Tras las vetas de la investigación cualitativa. Perspectivas y acercamiento desde la práctica. México DF: Instituto Tecnológico de Estudios Superiores de Occidente; 2003. p. 124-54.
28. Flick U. Observation and ethnography: an introduction to qualitative research. $5^{\text {th }}$ Ed. London: SAGE; 2014.

29. Marshall C, Gretchen BR. Designing qualitative research. 5th Ed. London: SAGE; 2010.

30. River J, Fisher M. Theorized life histories: masculinity and male suicide. In: Chesnay M, editor Nursing research using life history: qualitative designs and methods in nursing. New York: Springer Publishing Co.; 2015. p. 155-68.

31. Tojar HJ. Investigación cualitativa: comprender y actuar. Madrid: La Muralla; 2006.

32. Consejo Nacional de Población. Índices de intensidad migratoria México-Estados Unidos. http:// www.conapo.gob. $\mathrm{mx} / \mathrm{swb} / \mathrm{CONAPO/Indices}$ de_intensidad_migratoria_Mexico-Estados_Uni dos_2010 accedido el 12/May/2012).

33. Programa de las Naciones Unidas para el Desarrollo. Informe sobre desarrollo humano 2010. La verdadera riqueza de las naciones: caminos al desarrollo humano. http://hdr.undp.org/en/media/ HDR_2010_ES_Complete_reprint.pdf34) (accedido el 19/Jul/2011).

34. Bordieu P. La dominación masculina. Barcelona: Editorial Anagrama; 1998.

35. Brown J, Walkatle S. Handbook of sexual violence. New York: Routledge; 2012.

36. Frías SM. Gender, the state and patriarchy: partner violence in Mexico. Saarbrücken: Proquest; 2008.

37. Herrera C. Invisible al ojo clínico: violencia de pareja y políticas de salud en México. México DF: Facultad Latinoamericana de Ciencias Sociales; 2014.

38. Camus M. Fronteras, comunidades indígenas y acumulación de violencias. Desacatos 2012; (38):73-94.

39. Martínez RD, Obregón VN, Rivera HM. Relaciones de género violentas en contextos migratorios: perspectivas psicosociales para su abordaje. Ra Ximhai 2014; 10:17-41.

40. Arzate SJ, Vizcarra BI. De la migración masculina transnacional: violencia estructural y género en comunidades campesinas del Estado de México. Migración y Desarrollo 2007; (9):95-112.

41. Obregón-Velasco N, Rivera-Heredia M, MartínezRuiz D, Cervantes-Pacheco E. Sucesos estresantes y sus impactos en mujeres y jóvenes de la comunidad de Cuitzeo, Michoacán. El ciclo de la migración México-EUA en sus familias. REMHU Revista Interdisciplinar de Mobilidade Humana 2014; 22:211-24.

42. Mantecón MT. Hogares infernales: una visión retrospectiva sobre la violencia doméstica en el mundo moderno. Madrid: Universidad Salamanca; 2014.

43. Sánchez GM, Barceló QR. Mujeres indígenas migrantes: cambios y redefiniciones genéricas y étnicas en diferentes contextos de migración. Amérique Latine Histoire et Mémoire 2008; (14). http:// alhim.revues.org/2292.

44. Rincón RL. Honor femenino y economía de bienes simbólicos en Maracaibo, Venezuela a finales del siglo XIX (1880-1900). Revista de Antropología Iberoamericana $2008 ; 3: 218-48$ 
45. Rivas A, Gonzálvez H. El papel de las remesas económicas y sociales en las familias transnacionales colombianas. Migraciones Internacionales 2014; 6:75-99.

46. Juárez C, Valdez R, Hernández D. Las redes sociales y la noción de apoyo social en mujeres con experiencia de violencia conyugal, la percepción del apoyo social en mujeres con experiencia de violencia conyugal. Revista Salud Mental 2005; 28 : 66-8.

\begin{abstract}
Violence against women is a worldwide problem due to its impact on quality of life for those living under the complicity of a patriarchal culture and a state that makes such violence invisible. This article aims to give visibility to the contexts of violence affecting female "partners of migrants" in their places of origin, problematizing how such violence assaults their physical and mental health. This was a qualitative study with an interpretative anthropological focus, drawing on a sample of 21 women from rural and urban areas in San Luis Potosí, Mexico. Interviews were based on daily life history and discourse analysis. According to the results, women experience more violence when their spouses migrate, new forms of violence are committed against them, and the violence occurs in both the household and the community. Violence against women is a public health problem that should be treated through a framework that is sensitive to the social and cultural dynamics characterizing the contexts in which health programs are implemented.
\end{abstract}

Violence Against Women; Women's Health; Emigration and Immigration
47. Loza TM, Vizcarra BI, Lutz BB, Quintanar GE. Jefaturas de hogar: el desafío femenino ante la migración transnacional masculina en el sur del Estado de México. Migraciones Internacionales 2007; 4:33-60.

48. Cervantes PE, Rivera HM, Obregon VN, Martínez $\mathrm{RD}$. La feminización de los procesos migratorios internacionales: una perspectiva psicosocial de la migración de mujeres mexicanas a los Estados Unidos y su relación con la salud mental. Revista de Educación y Desarrollo 2011; 17:89-95.

\section{Resumo}

A violência contra as mulheres é um problema mundial, devido ao impacto que tem na qualidade de vida daquelas que a sofrem, submetidas à cumplicidade de uma cultura patriarcal e um Estado que a deixa invisivel. Este artigo objetiva visibilizar os contextos de violência que sofrem as mulheres "casais de emigrantes" nas localidades de origem, problematizando de que forma atentam contra a saúde física e mental delas. Foi realizado um estudo qualitativo com uma abordagem na antropologia interpretativa com 21 mulheres das localidades rurais e urbanas de San Luis Potosí, México; foram feitas entrevistas desde a perspectiva da historia da vida cotidiana e análises do discurso. Os resultados mostram que as mulheres vivem uma maior violência quando seus parceiros emigram e novas formas de violência são cometidas contra elas, acontecendo tanto no âmbito doméstico, quanto no comunitário. A violência contra as mulheres constitui um problema de saúde pública que deve ser visto desde um quadro sensivel com as dinâmicas sociais e culturais que caracterizam os contextos em que se aplicam os programas de saúde.

Violência Contra a Mulher; Saúde da Mulher; Emigração e Imigração
Recibido el 21/Feb/2015

Versión final presentada el 12/Oct/2015

Aprobado el 22/Feb/2016 